\title{
Erratum to: A mixed methods feasibility study of nicotine-assisted smoking reduction programmes delivered by community pharmacists - The RedPharm study
}

Amanda Farley ${ }^{1}$, Sarah Tearne ${ }^{2}$, Taina Taskila ${ }^{3}$, Rachel H. Williams², Susan MacAskill ${ }^{4}$, Jean-Francois Etter ${ }^{5}$ and Paul Aveyard ${ }^{2 *}$

\section{Erratum}

Following publication of this article [1], it has come to our attention that the author, Susan MacAskill, has had her name captured incorrectly. The correct spelling is the aforementioned.

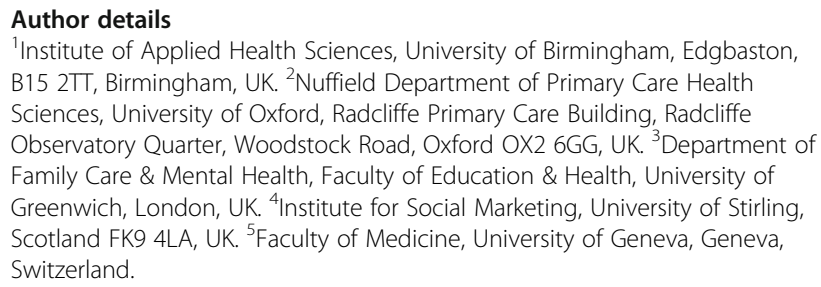

\section{Reference}

1. Farley A, Tearne S, Taskila T, Williams R, Mackaskill S, Etter J. Aveyard P (2017)

A mixed methods feasibility study of nicotine-assisted smoking reduction programmes delivered by community pharmacists-The RedPharm study. BMC Public Health. 2017;17:210. doi:10.1186/s12889-017-4116-z.

\footnotetext{
* Correspondence: paul.aveyard@phc.ox.ac.uk

${ }^{2}$ Nuffield Department of Primary Care Health Sciences, University of Oxford, Radcliffe Primary Care Building, Radcliffe Observatory Quarter, Woodstock Road, Oxford OX2 6GG, UK
} 